\title{
POTÊNCIAS ASCENDENTES, DECLINANTES E ESTAGNADAS: DESEQUILÍBRIO E EIXOS DE PODER MUNDIAL
}

\author{
DOI $10.29327 / 230731.12 .24-1$
}

\author{
Paulo Fagundes Visentini ${ }^{1}$
}

Resumo: A classificação da hierarquia e agrupamento das potências mundiais não se baseia, exclusivamente, em indicadores materiais como economia, recursos naturais, extensão territorial, dimensão populacional e recursos militares. É necessário considerar o estágio em que se encontra a transformação do sistema internacional pós-Guerra Fria, a posição que uma potência ocupa no mesmo e as tendências históricas gerais e específicas. O presente artigo propõe uma classificação que identifica a existência de quatro eixos de poder mundial: 1) o militar-rentista anglosaxão, 2) o industrial desenvolvido semi-soberano, 3) o industrial emergente

\section{Introdução}

A identificação das potências mundiais é algo corrente nos campos da Ciência Política e do discurso político-jornalístico. Todavia, na maioria das vezes ignora os elementos qualitativos e as dinâmicas intrínsecas à evolução da política internacional. Os estudos da área de Relações Internacionais e Defesa têm como um dos seus objetivos primordiais a mensuração do poder mundial, identificando e classificando hierarquicamente as grandes e médias potências. Os critérios utilizados para tanto são, todavia, bastante discutíveis, uma vez que se baseiam, predominantemente, em elementos quantitativos, organizados segundo teorias previamente estabelecidas, muitas vezes ahistóricas.

Geralmente levam em conta a superfície geográfica do país, suas riquezas naturais (agrícolas e minerais), o peso de sua economia (em geral o Produto Interno Bruto total e per capita) e o tamanho e estrutura de sua população. Também são considerados a posição geopolítica, o pertencimento à Organizações Internacionais influentes (G-7, OCDE, OTAN, CSONU), a estabilidade político-institucional e, last but not the least, a dimensão e qualidade das Forças Armadas. Geralmente esses itens são quantificados e tabelados, produzindo um ranking das potências e, a partir daí, uma série de

\footnotetext{
1 Professor Titular de Relações Internacionais na UFRGS, Pesquisador do CNPq, Coordenador do Núcleo Brasileiro de Estratégia e Relações Internacionais/NERINTUFRGS e Coeditor da Austral: Brazilian Journal of Strategy and International Relations.paulovi.ufrgs@gmail.com
} 
reflexões estratégicas e cenários geopolíticos. (Merle: 1981, 119, Morgenthau: 2003, 215, Kennedy: 1989, 417, Carr: 1981, 99)

Sem dúvida, trata-se de elementos basilares, mas a forma como se articulam e sua importância relativa estão relacionadas com outros elementos qualitativos. Em primeiro lugar, há a evolução histórica (cada Estado-Nação tem suas características específicas), o nível de desenvolvimento social e econômico, o grau de articulação das elites no poder, a existência de um projeto nacional, as conexões internacionais e o posicionamento no sistema mundial, entre outros. (Halliday: 2007, Wallerstein: 2004, 21, Arrighi: 1996, 59, Brucan: 1974, 140)

Um país pode possuir um poder militar expressivo e uma economia de grande porte, mas se encontrar em declínio por uma transformação na economia mundial e pelo surgimento de polos de poder desafiantes. Além disso, apesar de ser detentor de uma economia forte e capacidade militar quantitativa, algumas vezes têm limitações de soberania, que dificultam a conversão desses elementos em um instrumento eficaz de ação. A tabulação dos elementos materiais de poder pode gerar, assim, uma concepção estatística errônea e uma apreciação estratégica equivocada.

$\mathrm{Na}$ época moderna e contemporânea, com o surgimento e afirmação do sistema mundial, formaram-se na Europa os Estados Dinásticos Absolutistas, os players do Ancién Régime. Depois, a Revolução Francesa introduziu o elemento ideológico (mudança radical $x$ conservadorismo) e nacional nas Relações Internacionais. O Congresso de Viena (1815), por sua vez, introduziu a noção de Equilíbrio de poder entre as Potências (Grã-Bretanha, França, Rússia, Prússia e Império Áustro-Húngaro (Kissinger: 1973). Paralelamente, emergia o nacionalismo e o Estado-Nação. Mais tarde, como resultado da Primeira e da Segunda Guerras Mundiais, as potências europeias passaram a ser consideradas potências médias (especialmente quando perderam seus impérios coloniais), enquanto os Estados Unidos e a Rússia (transformada em União Soviética) se tornaram superpotências. Alguns Estados do Sul Geopolítico (Terceiro Mundo) também foram incluídos no rol das potências médias (ou regionais). Mas os paradigmas explicativos e a realidade internacionais se tornaram fluídos com o encerramento da Guerra Fria.

Assim, o que já era complicado numa fase de liderança reconhecida e de hegemonia, no quadro de uma fase de transição pode ser ainda mais complexo e incerto. Nesse sentido, o objetivo do presente capítulo é o de buscar contribuir para uma compreensão da posição de poder dos Estados no 
quadro do sistema internacional pós-Guerra Fria, em particular no século XXI. Trata-se de uma visão exploratória, objetivando dar conta das ações em curso e de possíveis tendências para o futuro imediato, no contexto da crise da economia desde 2008 e da desarticulação em curso da própria "globalização".

Mais do que por rivalidades ideológicas ou geopolítica, o que conta é a posição político-econômica que ocupam na estrutura de poder mundial. Nesse contexto, o primeiro grupo da política internacional contemporânea se aglutina no eixo militar-rentista anglo-saxão: Estados Unidos, Canadá, Reino Unido, Austrália, Nova Zelândia e, tangencialmente, Israel. Trata-se das nações hegemônicas que detém recursos militares, diplomáticos, financeiros, tecnológicos, de inteligência e de comunicações. Estando na fase pós-industrial rentista, vive dos recursos das demais nações, empregando para tanto os meios acima mencionados.

O segundo é o eixo industrial desenvolvido da União Europeia, Japão e Tigres Asiáticos. Com um capitalismo industrial produtivo avançado e elevado nível de vida de suas populações, ele se diferencia do primeiro, pois esse grupo carece dos recursos de poder tradicionais, como os militares, e de plena soberania. Foram protegidos durante a Guerra Fria, mas hoje a situação é incerta e as tensões com o primeiro são crescentes. Muito do que vier a ocorrer depende da atitude política a ser adotada por nações relevantes do eixo, como a Alemanha e o Japão, os derrotados da Segunda Guerra Mundial.

O terceiro consiste no eixo industrial heterodoxo emergente, integrado pelas grandes nações do BRICS, especialmente a China e a Rússia, além da Turquia e do Irã, onde as estruturas de poder e a participação do Estado na economia é relevante. Trata-se do que se denomina semiperiferia. Como o anterior, seu objetivo imediato e prioritário é o de evitar um conflito armado de dimensões globais e manter seu desenvolvimento econômico. Com recursos para se defender, eles não conseguem projetar poder em escala planetária e dependem, em certa medida, da atitude que vier a ser adotada pelo segundo eixo.

Por fim, o quarto é o eixo agrário, mineral e demográfico periférico, integrado pelas nações médias e pequenas da América Latina, da África e da Ásia geográfica (que inclui o Oriente Médio). Possuem recursos humanos, agrícolas ou minerais abundantes (inclusive energia) mas não detém capacidade militar ou articulação diplomática, tendendo a agir de maneira fragmentada e constituindo uma zona em disputa pelos demais eixos. O Brasil e a África do Sul parecem estar absorvidos por suas agendas políticas internas e correm o risco de passar a integrar esse grupo. 


\section{O eixo militar-rentista anglo-saxão dominante}

O grupo dominante da política mundial é integrado no eixo militarrentista anglo-saxão: Estados Unidos, Canadá, Reino Unido, Austrália e Nova Zelândia. Mais do que uma simples "comunidade linguística", ele representa uma continuidade dos Impérios Marítimos e de sua geopolítica. Ele é o herdeiro da hegemonia liberal britânica do século XIX e de seu império colonial posterior, bem como das alianças (e dos resultados) das duas Guerras Mundiais contra as potências médias (Alemanha e Japão) e da Guerra Fria antissocialista/antissoviética.

Trata-se das nações coletivamente em posição hegemônica, as quais detém recursos militares, diplomáticos, financeiros, tecnológicos, de inteligência e de comunicações logísticas e informacionais. Tendo atingido a fase pós-industrial rentista (no último quarto do século $\mathrm{XX}$ ), depende de recursos das demais nações, empregando para tanto os meios acima mencionados. Com a atual Revolução Científico-Tecnológica em curso, particular atenção deve ser dada aos três últimos aspectos, que tem revolucionado as relações internacionais e os sistemas de defesa.

O acordo chamado UKUSA (Reino Unido e Estados Unidos da América), estabelecido na segunda metade dos anos 1940 entre Washington e Londres, deu origem ao sistema de informações e espionagem eletrônica Echelon, conhecido como tal nos anos 1980. Esse sistema, baseado na Inglaterra, recolhe, processa e compartilha informações entre os países que constituem os Cinco Olhos: Estados Unidos, Canadá, Reino Unido, Austrália e Nova Zelândia. Anteriormente voltado a questões militares contra o Pacto de Varsóvia durante a Guerra Fria, ele passou nos anos 1980 a incluir a espionagem industrial e política, inclusive em relação a aliados na OTAN na União Europeia, como foi denunciado no Parlamento Europeu em 2000 (SILVA: 2018).

Ele não engloba apenas o território metropolitano desses países, mas um conjunto de pequenas ilhas e pontos estratégicos em todos os Oceanos e continentes. Um dos pontos do sistema de espionagem mundial Echelon, por exemplo, se localiza na ilha britânica de Ascensão, no centro do Oceano Atlântico. Trata-se não apenas de "antenas" do sistema, mas igualmente de bases militares e/ou Paraísos Fiscais, os últimos conectados à praça financeira de Londres. O Reino Unido soube se adaptar ao seu declínio hegemônico, através de uma aliança com os Estados Unidos, com ambos os países convergindo nas votações do Conselho de Segurança da ONU. 
Os Estados Unidos constituem a liderança do grupo, com o dólar, a diplomacia, as forças armadas, a indústria cultural e o controle quase exclusivo dos meios de comunicação eletrônica e de Organizações Internacionais. Mas os demais não são "dominados", mas sim partes integrantes e ativas (embora discretas) do grupo. Israel, tangencialmente, está associado ao grupo, mas tem uma agenda regional própria, mantém certa independência e é uma potência nuclear. Há também apêndices europeus associados, do ponto de vista estratégico, como Espanha, Portugal, Holanda, Dinamarca, Polônia, Hungria, Croácia, Romênia, Bulgária e os países Bálticos (Lituânia, Letônia e Estônia).

Embora sejam membros da União Europeia, assim como o Reino Unido até o Brexit, seu foco na área de Defesa tem sido a convergência com o eixo anglo-saxão. No Sul Geopolítico (Terceiro Mundo) podem ser mencionados Chile, Colômbia, Marrocos, Quênia e Arábia Saudita (mas Riad tem margem de autonomia) como parceiros do eixo e agendas de "aliados regionais" do mesmo, exercendo influência em seu entorno. Mas esses países não possuem os requisitos de poder anteriormente enumerados para serem integrantes do grupo ou capacidade de influir nas decisões e estratégias ou são desejados como sócios pelos Big Five? ${ }^{2}$.

\section{O eixo industrial desenvolvido semi-soberano}

O segundo grupo é o eixo industrial desenvolvido da União Europeia, Japão e Tigres Asiáticos. Com um capitalismo industrial produtivo avançado e elevado nível de vida de suas populações, ele se diferencia do primeiro, pois esse grupo carece dos recursos de poder tradicionais (exceto a França), como os militares, e de plena soberania. Foram protegidos durante a Guerra Fria, mas hoje a situação é incerta e as tensões com o primeiro eixo são crescentes. Muito do que vier a ocorrer depende da atitude política a ser adotada por nações relevantes do eixo, como a Alemanha e o Japão, os derrotados da Segunda Guerra Mundial, e da França, que tem se revelado incapaz de agir estrategicamente de forma coerente.

Sua composição se baseia nas antigas potências médias que se industrializaram na final do século XIX (Europa Central e Japão) e após a Segunda Guerra Mundial (restante da Europa e Tigres Asiáticos). Durante a Guerra Fria foram enquadradas como membros da OTAN (Europa) ou Pactos

\footnotetext{
${ }^{2}$ Alusão aos cinco animais africanos capazes de se defender sozinhos: o leão, o elefante, o búfalo, o rinoceronte e o leopardo. No caso, trata-se dos Estados Unidos, Canadá, Reino Unido, Austrália e Nova Zelândia.
} 
bilaterais de defesa na Ásia Oriental. E, no caso dos integrantes do Eixo fascista (Berlim, Roma e Tóquio), há sérias limitações institucionais e militares à plena soberania. Não se trata apenas das tropas e bases militares americanas em seu território (algumas em nome da OTAN), mas dos óbices à constituição de uma tecnologia e indústria bélica e aeroespacial própria. Também pesa muito o fato de serem Estados reconstituídos por forças de ocupação após 1945, com uma elite moldada pelos vencedores, hoje dividida e sem visão estratégica.

O caso francês é emblemático, pois, entre os países desse eixo, detém uma posição única: potência nuclear, membro permanente do Conselho de Segurança da ONU, detentora de uma rede de bases ao redor do mundo e de uma tecnologia e indústria aeroespacial independente. Com a Alemanha forma o hard core da União Europeia, mas desde os anos 1970 parece mergulhada numa crise de identidade estratégica. Já na Alemanha e no Japão, com tecnologia e economias ultra avançadas, as elites parecem sofrer da síndrome do pós-Guerra Fria, sem conseguir definir um projeto coerente de ação internacional. O caso da relação da Alemanha com a Rússia e os Estados Unidos é emblemático, com interesses econômicos convergindo com Moscou e a agenda de defesa seguindo vinculada a Washington.

Na Ásia Oriental, com Japão, Coreia do Sul e Taiwan, ocorre o mesmo em relação aos Estados Unidos e à China. Crises militares artificialmente fomentadas mantém um estado de insegurança permanente, visando limitar a convergência entre os Tigres e o Dragão chinês. Para tanto, basta provocar a Coreia do Norte, que reage da forma esperada e desejada, para manter 0 alinhamento aos esquemas securitários de Washington. Todavia, a "Guerra Comercial" entre os EUA de Trump e a China significa mais uma disputa de renegociação entre parceiros, pois o real conflito econômico e tecnológico, muito mais complexo e multidimensional, está ocorrendo entre os Estados Unidos e a União Europeia, em particular a Alemanha.

$\mathrm{Na}$ mesma linha, vale lembrar que Samuel Huntington (1997: 195) definiu que o coração do Ocidente se encontrava no Atlântico Norte e que a OTAN era sua organização articuladora. Assim, o dilema da União Europeia e do Japão/Tigres é que suas relações econômicas com os EUA enfraquecem, enquanto crescem com os BRICS, particularmente China e Rússia. Mas os vínculos diplomáticos-securitários com Washington, bem como o arranjo entre as elites dirigentes das duas margens do Pacífico, seguem fortes.

As Revoluções Coloridas chegaram à Europa, com Brexit, movimentos políticos "populistas" no poder e violência radical desestabilizadora (como os Coletes Amarelos franceses), bem como desrespeito aberto às normas 
comunitárias, atentados terroristas, separatismos e migrações massivas induzidas formando parte de um mesmo processo. Evidentemente há uma base sociológica para tal fenômeno, com o gradual naufrágio do Estado de Bem-Estar Social e o esvaziamento do universo da política tradicional, mas há uma sincronização. Steve Bannon não é um "rebelde sem causa".

\section{O eixo industrial emergente semiperiférico}

O terceiro grupo consiste no eixo industrial emergente, integrado pelas grandes nações do BRICS, especialmente a China e a Rússia, além da Turquia e do Irã, onde a participação do Estado no desenvolvimento representam traços determinantes. Trata-se do que se do que é conceituado como semiperiferia, o alvo explícito dos Estados Unidos de Donald Trump e sua America First. Como o anterior, seu objetivo imediato é evitar um conflito armado de dimensões globais e manter seu desenvolvimento econômico. Com recursos para se defender, eles ainda não conseguem projetar poder militar global e dependem da atitude que o segundo eixo vier a adotar. Mas alguns deles têm poder de dissuasão e estão se tornando mais assertivos a medida em que a crise iniciada em 2008 e as tensões mundiais se aprofundam.

Rússia e China são membros permanentes do Conselho de Segurança da ONU e, assim como a Índia, potências nucleares. A China mantém seu regime socialista com um projeto de desenvolvimento multifacético globalizado, com altas taxas de crescimento, que já tornaram o país a segunda economia do mundo. E esse avanço produtivo está sendo acompanhado do incremento tecnológico e de capacidade de defesa. O Estado chinês abarca $22 \%$ da população mundial e goza de estabilidade interna e de autonomia internacional. E seu projeto de desenvolvimento "socialista de mercado" se semelhante à NEP soviética dos anos 1920 (Nova Política Econômica), só que internacionalizada. Suas conexões comerciais, financeiras e tecnológicas, tanto com os países capitalistas desenvolvidos como os em desenvolvimento, têm transformado a geoeconomia mundial, em particular nas áreas periféricas.

Já a Rússia representa mais uma potência reemergente, pois é herdeira da superpotência soviética derrotada, após severo enfraquecimento e declínio nos anos 1990. A capacidade tecnológica, a indústria aeroespacial e armamentista, bem como capacidade de defesa, a tornam o único Estado com capacidade de rivalizar estrategicamente com os Estados Unidos. Todavia, ela sofre de algumas debilidades, pois sua governança ainda é frágil. Ele não possui um partido estruturante (como na China ou na época soviética) e a 
sociedade sofreu grandes transformações e fragmentação. Além disso, do ponto de vista geopolítico, seu entorno (o "exterior próximo") e conexões internacionais denotam fragilidades, apesar da criação da União Econômica Eurasiana (que agravou o problema ucraniano).

Quanto ao Elefante indiano, observa-se um crescimento econômico e crescente presença internacional, mas com um desconcertante atraso social de sua população em acelerado crescimento, que ultrapassará a chinesa em poucos anos. A população chinesa está estabilizada e envelhece, enquanto a russa já envelheceu e regrediu numericamente. Mas esses dois países possuem amplos territórios e recursos naturais, ao contrário da Índia. Embora o status nuclear da Índia tenha sido chancelado pelos Estados Unidos, o país enfrenta graves desafios securitários tanto externos (China e Paquistão) quanto internos (terrorismo, separatismo e guerrilha maoísta Naxalita).

Brasil e África do Sul pós-Apartheid conheceram desenvolvimento acelerado no início do século XXI e, justamente com a Índia, criaram o Fórum de Cooperação Trilateral IBAS em 2003. Mas nos anos recentes ambas nações vivenciaram sérias crises de governabilidade e estagnação econômica, carecendo, atualmente, de um projeto estratégico. Da mesma forma, as duas nações perderam o seu protagonismo no campo da integração regional. $O$ Brasil, em particular, encontra-se no limiar de ser rebaixado ao quarto eixo, que será analisado adiante. Dois Estados que lograram avanços econômicos e político-militares foram a Turquia e o Irã, adquirindo uma posição e um status semelhantes ao dos BRICS. Mas ambos se encontram numa linha de fratura geopolítica extremamente vulnerável e denotam certa fragilidade doméstica e internacional.

Mas o BRICS, que adquiriu suas características de polo de poder em 2009 (em resposta aos desdobramentos da crise de 2008), tem desenvolvido mecanismos econômicos e diplomáticos consideráveis, embora não constituam um "bloco", e sim um fórum. Além de integrar nações do IBAS, há uma outra organização importante, que é a Organização de Cooperação de Xangai (OCX), surgida em 1996 engoblando China, Rússia, Cazaquistão, Quirguistão e Tadjiquistão. Posteriormente Uzbequistão, Índia e Paquistão passaram a integrar esse bloco (além de outros Estados observadores). Ela possui um foco econômico e securitário e articula um polo eurasiano, que representa um pesadelo estratégico para os EUA (Brzezinski: 1998). Todavia, Rússia e China são aliados, ma non tropo, pois ambos os países têm agendas parcialmente divergentes e competem na região.

As grandes nações emergentes constituem uma espécie de semiperiferia, onde a acumulação prévia de capital os coloca numa posição de 
projeção econômica global, gerando uma situação em que o crescente peso econômico conflitua com a ordem política mundial preexistente. A Rússia de Putin não é apenas uma potência energética (gás, petróleo e urânio), mas suas empresas internacionalizadas desse setor implicam em uma crescente presença internacional. Ao lado disso, Moscou voltou a ser um grande exportador de armamentos avançados. Já a China, além de sua crescente presença econômica na África e América Latina, lançou iniciativas eurasianas arrojadas como a Nova Rota da Seda e o OBOR (One Belt, One Road). Elas configuram a emergência de uma zona pivô terrestre, que recria os elementos básico da geopolítica clássica, com novos elementos econômicos.

\section{O eixo agrário, mineral e demográfico periférico}

Por fim, o quarto é o eixo agrário, mineral e demográfico periférico, integrado pelas nações médias e pequenas da América Latina, da África e da Ásia geográfica (que inclui o Oriente Médio). Possuem recursos humanos, agrícolas ou minerais abundantes (inclusive energia) mas não detém capacidade militar ou articulação diplomática, tendendo a agir de maneira fragmentada e constituindo uma zona em disputa pelos demais eixos. O Brasil e a África do Sul, integrantes do BRICS, parecem estar sendo "rebaixados", devido a suas agendas e disputas políticas internas, e correm o risco de passar a integrar esse grupo.

\section{Dimensões estruturais}

O Sul Geopolítico (Terceiro Mundo) abarca a América Latina, a África, a Ásia Ocidental (Oriente Médio), Central e Meridional, onde ocorre o crescimento demográfico mundial. Isso não apenas representa uma imensa reserva de mão de obra jovem e potencial mercado consumidor, mas gera, igualmente, um excedente populacional desocupado que produz crises migratórias e de refugiados de conflitos. A fronteira Estados Unidos-México e o Mar Mediterrâneo se tornaram zonas extremamente vulneráveis a esse fenômeno. $O$ arco que vai do Paquistão ao Japão (excluindo a metade ocidental da China) abriga mais da metade da população mundial. E o Oriente Médio e a metade norte da África vivem forte desestabilização.

Por outro lado, as democracias de consumo do Norte consomem enormes volumes de alimentos e matérias primas (energia e minérios, entre outras), cuja produção e reservas se encontram no Sul (Paiva: 2011, 32). Esse 
fenômeno se agrava ainda mais com o aumento do consumo per capita nas nações emergentes e das classes médias urbanas de todo o Sul Geopolítico. Nele se encontram vastos espaços para investimentos lucrativos (infraestrutura, mineração, serviços, agronegócio), num quadro de crescente competição intercapitalista, o qual opõe, principalmente, as antigas potências industriais e as emergentes da semiperiferia. Assim, essa parte do planeta é palco de uma disputa econômica e estratégica que se assemelha à que antecedeu a Primeira Guerra Mundial.

O Sul Geopolítico concentra, aproximadamente, dois terços dos Estados existentes (bastante desiguais), a maioria esmagadora deles com grande fragilidade político-social e debilidade militar e econômica. A agenda internacional desses consiste, simplesmente, na manutenção de sua existência como nação e das elites locais no poder. Muitas iniciativas de articulação da época da Guerra Fria, como o G-77 e o Movimento dos Países Não-Alinhados, que buscavam formular uma agenda comum e aumentar o peso político da região na ONU, perderam o foco com o fim da bipolaridade. Com o ciclo neoliberal da globalização, a partir dos anos 1990, foram formuladas várias iniciativas de integração regional, mas elas esbarraram em dificuldades estruturais no plano local e global. Assim, ainda que o PIB de muitas das nações do Sul esteja crescendo, às vezes acima da média mundial, a vulnerabilidade política, a instabilidade econômica e a tensão social é crescente.

Apesar das diferenças materiais e de alinhamentos em política externa, esses Estados têm em comum, estruturalmente, uma posição semelhante na economia mundial. De forma direta ou indireta, estão sujeitos às agendas formuladas pelas potências norte-atlânticas e às ações de Estados poderosos e de megaempresas transnacionais. Mas nas diversas regiões que compõem o Sul Geopolítico podem ser identificados alguns Estados-pivô, com certo protagonismo político e, eventualmente, econômico.

\section{$\underline{\text { Regiões e Estados-pivô }}$}

Na América Latina, após a "Onda Rosa" de governos de centroesquerda com agenda social (mas sem romper com o neoliberalismo), a tendência é a reversão (por vários meios) de quase todos eles. E juntamente com as mudanças internas, ocorre o esvaziamento dos projetos de integração (Mercosul) e de associação latino-americanos como a CELAC, bem como sulamericanos (UNASUL). O Brasil, como analisado, se encontra em uma situação política e econômica que o está conduzindo a uma posição de 
membro gigante desse quarto eixo, enquanto a Argentina já se encontra nele há algum tempo.

$\mathrm{Na}$ América do Sul o Chile e a Colômbia mantêm um protagonismo estratégico pró-Washington, o primeiro com seu exército poderoso e posição geopolítica bioceânica. A segunda, com longa cooperação com os EUA em contra-insurgência e combate ao narcotráfico, hoje joga um papel relevante na crise Venezuelana. Já o México, embora siga integrado subordinadamente à economia dos Estados Unidos, exerce uma espécie de "protagonismo negativo ou involuntário", com a questão migratória e do narcotráfico jogando um papel importante. Já o maior interesse da administração Trump no subcontinente é a agenda econômica e a contenção da crescente presença chinesa, com seus investimentos, serviços, comércio e construção de infraestrutura.

A África, muito mais do que a Ibero-América, hoje representa uma região em acirrada disputa geopolítica entre potências antigas e emergentes, o que inclui o espaço estratégico dos Oceanos Índico e Atlântico Sul. A isso se soma o terrorismo na sua metade norte, golpes de Estado, guerras civis como na República Democrática do Congo e Sudão do Sul e o colapso de Estados como a Líbia e a Somália. O Marrocos segue como um aliado Ocidental estratégico, com a questão pendente do Saara Ocidental e sua campanha, como um "Cavalo de Tróia" no Sul, em prol da chamada Comunidade Atlântica (unindo os cenário norte-atlântico com o sul-atlântico). Já a África do Sul se encontra estrategicamente estagnada pelos efeitos de sua transição pactuada de saída do Apartheid, já não sendo mais a maior economia do continente, posição hoje ocupada pela populosa Nigéria.

Todavia, o continente possui uma dinâmica própria e Estados que avançam econômica e politicamente. Angola, Nigéria e Etiópia se tornaram algo que, no contexto africano, poderia ser considerado como potências regionais. Ironicamente, os Organismos de Cooperação africanos têm desempenhado um papel crescente na cooperação econômica e resolução de conflitos. Djibuti, por sua vez, se tornou um ponto nevrálgico, não apenas por sua posição geopolítica na entrada do Mar Vermelho, mas por abrigar bases de países como França, EUA e China. O Quênia, igualmente, constitui um ponto de apoio estratégico Ocidental. O Golfo da Guiné, com seus recursos petrolíferos, também se tornou uma região estratégica. A clivagem principal no continente opõe os Estados Unidos e a França à crescente presença chinesa. Mas, ao contrário de certa narrativa vitimizadora, o que se observa é que tal situação tem conferido aos Estados africanos uma margem de autonomia política e econômica que nunca haviam disfrutado em 60 anos de vida independente (Visentini: 2013). 
O Oriente Médio, assim como a África, constitui uma região em acirrada disputa estratégica, por sua posição geopolítica e recursos energéticos, só que de forma muito mais direta e violenta. Embora isso não seja algo inédito, atualmente possui um novo significado, não mais de antagonismos confinados regionalmente. Transformou-se no Grande Oriente Médio, com a inclusão dos novos Estados do Cáucaso (Geórgia, Armênia e Azerbaijão) e da Ásia Central ex-soviética e Afeganistão, palco do novo Grande Jogo ou Grande Tabuleiro. A Geórgia, o Azerbaijão, o Turcomenistão e o conflituado Afeganistão constituem um corredor pró-OTAN que separa a Rússia e seus aliados da Ásia Central dos também aliados Irã, Armênia e Síria.

A Turquia, aparentemente, desistiu da aproximação com a União Europeia e se aproximou da Rússia e do Irã, que é considerado uma ameaça por Israel, Arábia Saudita e as petromonarquias do Golfo, exceto Catar e Omã. As clivagens políticas domésticas do lêmen (bloqueado por Riad e devastado pela guerra civil) foram enquadradas pelo Irã e pela Arábia Saudita. O Reino saudita vive uma luta interna dentro da elite dirigente (dezenas de facções de Príncipes rivais) e constitui uma teocracia fundamentalista e monarquia absolutista que assumiu sua associação com Israel. $O$ país possui enorme importância petrolífera, financeira e é mentor e financiador de movimentos islâmicos fundamentalistas. Além das guerras civis internacionalizadas da Síria e do lêmen, o Iraque segue sendo um terreno de embate, com a questão curda ocupando uma posição central.

Todavia, seria errôneo pensar que se trata de um embate entre sunitas e Ocidente contra xiitas. O que está em jogo é a tentativa das monarquias conservadoras e das potências Ocidentais de derrubar os regimes laicos e modernizantes, que incluem a Síria, o lêmen, o Egito, o Irã (que é modernizante) e a Turquia, que esfriou sua relação com a OTAN e se aproximou da Rússia. A intervenção formalmente "antiterrorista" Ocidental no Iraque e no Afeganistão redundou em um fracasso e a tentativa de derrubada do Regime do Baas na Síria, igualmente, não teve êxito, abrindo espaço para a Rússia na região.

Na Ásia meridional, além da Índia já analisada, o Paquistão (potência nuclear) tem se aproximado da China e do Irã. Mas é digno de nota o protagonismo e autonomia relativa dos 10 Estados integrantes da Associação das Nações do Sudeste Asiático (ASEAN). Formada por países ricos (Cingapura e Malásia) e pobres (Filipinas), monarquias e repúblicas, grandes e pequenos, socialistas e capitalistas, estáveis e instáveis e regimes democráticos a la Ocidental (Tailândia) e considerados autoritários (Mianmar), a ASEAN logra desenvolver uma agenda política autonomista comum. A 
Associação representa um ponto de equilíbrio entre as gigantes China e Índia, apesar das tensões no Mar da China Meridional. Já na península coreana (junto com o Japão) as tensões locais se encontram enquadradas em antagonismos globais.

O imenso espaço do Oceano Pacífico está sob controle das potências marítimas, com a Austrália (chamada na região de "EUA do Pacífico") e a Nova Zelândia exercendo um papel importante, com o controle de inúmeros arquipélagos, assim como os Estados Unidos, a França e o Reino Unido. $O$ Oceano Índico constitui, por sua vez, um espaço em disputa, com as três últimas nações (mais a Austrália) ocupando uma posição dominante, mas tendo que fazer frente à crescente presença naval chinesa e russa. Já o Atlântico Sul, por sua vez, tem seus pontos estratégicos no centro do mesmo e nas passagens para os demais oceanos sob discreto controle do Reino Unido. Por fim, mesmo os espaços polares ártico e antártico se converteram em regiões em que a presença econômica e militar das potências capitalistas desenvolvidas rivaliza com a das emergentes.

\section{Estruturas, processos e tendências}

O encerramento da Guerra Fria e do seu Sistema bipolar produziu novas realidades e desafios teóricos. Muitas tentativas de interpretação foram buscadas, mas parece claro que os EUA e as potências anglo-saxônicas que compõe o primeiro eixo de poder seguem dominantes, mas em um quadro de acelerada mutação e tendente à multipolaridade. Assim como Kissinger (1973) muito bem definiu em sua tese de doutorado o equilíbrio europeu de poder, no início do século XXI há um Equilíbrio (instável) de Poder Global. Há dois níveis de clivagens internacionais, não exatamente superpostas: um político e outro econômico, que denotariam uma assincronia entre a estrutura de poder político e a de poder econômico.

As clivagens políticas, que afetam a distribuição do poder mundial, opõem China e Rússia (ou o núcleo duro dos BRICS) de um lado e as potências anglo-saxônicas de outro, tendo o grupo União Europeia/Japão como aliados recalcitrantes. Já as clivagens econômicas, vão além da visão de "emergentes versus declinantes", como a administração Trump está demonstrou. É certo que a Ásia se tornou o grande centro manufatureiro industrial mundial, mas a economia internacional possui uma dinâmica integrada e, contraditoriamente, conflitiva (desenvolvimento desigual e combinado). E o sistema mundial se caracteriza, como demonstrou Arrighi 
(1996), pela coexistência entre Estados territoriais e o capital, com mobilidade transnacional.

Assim, se por um lado, na condição de Estados nacionais, os emergentes reclamam por uma fatia de poder compatível com seu crescente peso econômico, por outro, eles se encontram associados às grandes nações já desenvolvidas ou pós-industriais. Nesse contexto, a "Guerra Comercial" EUA-China, se assemelha à EUA-Japão dos anos 1980. A China possui uma relação simbiótica com os Estados Unidos e a disputa atual parece conter elementos de renegociação do "pacto" econômico entre ambos. O verdadeiro alvo da agressividade americana é a Europa nucleada em torno da Alemanha (concorrente de capitalismo avançado) e o reenquadramento de Estados semiperiféricos de sua região de controle geopolítico (caso do Brasil).

Isso não significa que tudo seguirá como era e que o poder americano/anglo-saxão tende a manter sua posição dominante. $\mathrm{O}$ historiador e demógrafo Emmanuel Todd (2003:4) argumentou que

\begin{abstract}
"não haverá império americano. O mundo é demasiado vasto, diverso e dinâmico para aceitar a predominância de uma única potência. $O$ exame das forças demográficas e culturais, industriais e monetárias, ideológicas e militares que transformam o planeta não confirma a atual visão de uma América invulnerável. (...) Um quadro realista [mostra] uma grande nação cuja potência foi incontestável, mas que o declínio relativo parece irreversível. Os Estados Unidos eram indispensáveis ao equilíbrio do mundo; eles não podem hoje manter seu nível de vida sem os subsídios do mundo. A América, pelo seu ativismo militar de teatro, dirigido contra Estados insignificantes, tenta mascarar seu refluxo. A luta contra o terrorismo, o Iraque e o 'eixo do mal' não são mais do que pretextos. Porque ela não tem mais a força para controlar os atores maiores que são a Europa e a Rússia, o Japão e a China, a América perderá esta última partida pelo domínio do mundo. Ela se tornará uma grande potência entre outras"
\end{abstract}

As transformações geradas pelo mundo pós-moderno e neoliberal atingiram os países de forma diferenciada. O eixo anglo-saxão possui uma economia pós-industrial (finanças, tecnologia, serviços) que é mais administrativa (equilibrar orçamento), enquanto o eixo desenvolvido e o eixo emergente são produtivos (produtores de mercadorias). Já no Sul o enfraquecimento do Estado, o excedente populacional e o desenvolvimento insuficiente provocam criminalidade crescente e emigração, mas não dos mais miseráveis.

Além disso, as consequências sociais alteram a estrutura da sociedade. Enquanto no Norte as cidades se degradam (Detroit é o caso mais radical), no Sul surgem caóticas megalópoles, com criminalidade e poluição. $O$ consumo de drogas em escala cada vez maior, além de um negócio lucrativo, representa 
uma forma de controle social da juventude, que reflui para nichos e não se envolve em política, tanto no Norte como no Sul. A terceirização e o trabalho fragmentado por aplicativo, bem como o "empreendedor" da "economia criativa" substituem a antiga classe trabalhadora sindicalizada.

De que forma esse estágio do capitalismo afeta as relações internacionais e a hierarquia entre potências? A imigração transforma o Norte por dentro, assim como ocorreu com o Império Romano, só que de forma diferente. Em Estados pós-coloniais, historicamente receptores de imigrantes (como Brasil e EUA) há certa assimilação, enquanto na Europa surgem crescentes tensões, em uma sociedade envelhecida e sem novos projetos políticos. Já no Sul, produtor de insumos, a atitude das elites é diferenciada, sendo o pior caso o da América Latina, que se encontra sem projeto e em acentuado retrocesso econômico. Com a Revolução Tecnológica e o avanço de outras regiões, está se formando um gap irrecuperável.

$\mathrm{Na}$ África e no Oriente Médio pós-Primavera Árabe parece haver uma recomposição das elites dirigentes, com a sinalização de novos projetos nacionais e de alteração de alianças internacionais. Como Todd (2003) demonstra em sua obra, o mundo árabe e islâmico se encontra em processo de modernização demográfica e política. Na Ásia, especialmente na oriental, há realmente projetos e elites mais comprometidas com o desenvolvimento, apesar das contradições sistêmicas. Curiosamente, pouco se fala sobre o fato do país com melhor performance econômica há décadas ser a República Popular da China, um Estado socialista.

A formação de um amplo espaço eurasiano interconectado (que acessa - Oriente Médio por terra) parece ser o grande temor dos estrategistas norteamericanos e de seus aliados. Com uma América que perde sua utilidade para as demais nações, até quando o "antiterrorismo" seguirá sendo um vetor de ação eficaz? Nada parece lograr uma atualização da estrutura das Nações Unidas e surgem lideranças aventureiras e as tensões se acumulam, na ausência de estratégias definidas. Para completar, em 2020 o mundo foi sacudido pela pandemia do Covid-19, produzindo uma situação de agudização da crise que já se esboçava em 2019. A realidade que emergirá após a pandemia é de difícil previsão. Pode haver mudanças, mas também "mais do mesmo" pois, em 150 anos, os grupos políticos "progressistas" nunca estiveram tão carentes de uma agenda realista e o cenário pós-Trump ainda está por se definir. Assim, mais do que nunca é necessário refletir sobre as transformações em curso e seu impacto no jogo entre as grandes potências. 
Referências

ARRIGHI, Giovanni. O longo século XX: Dinheiro, poder e as origens do nosso tempo. Rio de Janeiro/ São Paulo: Contraponto/Unesp, 1996.

BRUCAN, Silviu. La disolución del poder mundial. Sociologia de las relaciones internacionales y política. Mexico: Siglo XXI, 1974.

BRZEZINSKI, Zbigniew. El Gran Tablero Mundial. La supremacia estadounidense y sus imperativos geoestratégicos. Barcelona: Paidós, 1998.

CARR, Edward. Vinte anos de crise: 1919-1939. Brasília: Ed. UnB, 1981

HALLIDAY, Fred. Repensando as Relações Internacionais. Porto Alegre: Ed. Da UFRGS, 2007.

HUNTINGTON, Samuel. O choque de Civilizações e a recomposição da ordem mundial. Rio de Janeiro: Objetiva, 1997.

KENNEDY, Paul. Ascensão e queda das grandes potências: Transformação econômica e conflito militar de 1500 a 2000. Rio de Janeiro: Campus, 1989.

KISSINGER, Henry. O mundo restaurado. Rio de Janeiro: José Olympio, 1973.

MERLE, Marcel. Sociologia das Relações Internacionais. Brasília: Ed. Universidade de Brasília, 1981.

MORGENTHAU, Hans. A política entre as nações. Brasília: Ed. Da UnB, 2003.

PAIVA, Luiz Eduardo Rocha. "Principais áreas de friç̧ão no mundo atual: reflexos para a defesa nacional", in ACIOLY, Luciana, e MORAES, Rodrigo de (Orgs). Prospectiva, estratégias e cenários globais. Brasília: IPEA, 2011.

SILVA, Antonio Ruy de Almeida. A Diplomacia de Defesa na Política Internacional. Porto Alegre: Palmarinca/ Rio de Janeiro: ESG, 2018.

TODD, Emmanuel. Depois do Império: a decomposição do sistema americano. Rio de Janeiro: Record, 2013.

VISENTINI, Paulo. A África e as potências emergentes. Porto Alegre: Leitura XXI/ Cebráfrica-UFRGS, 2013.

WALLERSTEIN, Immanuel. O declínio do poder americano. Rio de Janeiro: Contraponto, 2004. 